\title{
Serum-Prolactin and the Association to Disease Activity in Patients with Rheumatoid Arthritis
}

\author{
Hans-Jacob Haga ${ }^{1}$, Alicia Martin Moreno ${ }^{2}$, Dorte Terp Andersen ${ }^{3}$ \\ and Elisabeth Peen ${ }^{1}$ \\ ${ }^{1}$ Aalborg University Esbjerg, 6700 Esbjerg, Denmark \\ ${ }^{2}$ Department of urology, The National Hospital, Copenhagen, Denmark \\ ${ }^{3}$ Clinical molecular diagnostic laboratory, Sydvestjysk sygehus, Esbjerg, Denmark
}

Correspondence should be addressed to: Hans-Jacob Haga; hjh@reumaklinikdanmark.dk

Received Date: 11 November 2013; Accepted Date: 25 March 2014; Published Date: 29 April 2014

Academic Editor: Athina Pyrpasopoulou

Copyright (C) 2014 Hans-Jacob Haga, Alicia Martin Moreno, Dorte Terp Andersen and Elisabeth Peen. Distributed under Creative Commons CC-BY 3.0

\begin{abstract}
The objective of this article is to analyze the serum level of Prolactin (s-PRL) in 307 treated patients with Rheumatoid Arthritis (RA), and its association to disease activity, demographics, serological and clinical variables.

The hypothesis to be tested: s-PRL correlates to disease activity in RA.

Serum concentration of the hormone Prolactin (s-PRL) was determined in 307 treated patients with (RA) in a cross-sectional study design. The patients were characterized by demographic, serological and clinical variables, in addition to assessment of disease activity by DAS28 (3wCRP) score. Prolactin was analyzed by a double sandwich immune analysis.

Among the 307 RA-patients examined, only 4 patients had high s- PRL defined as females $>637$ $\mathrm{mIU} / \mathrm{L}$, and males $>456 \mathrm{mIU} / \mathrm{L}$. These 4 patients all had low disease activity score (DAS 28 score $<2,0)$. There was no correlation of s-PRL to DAS28 score ( $r=-0,08, p=0.21)$, and no correlation of s-PRL to the number of swollen or tender joints, pain, CRP, Rheumatoid factor or anti-CCP.

We demonstrated that 4 out of 307 RA patients had high level of s-PRL, all of them with low disease activity score. No correlation of s-PRL to disease activity DAS 28 score was demonstrated. We therefore question the hypothesis that PRL may play a role in disease severity and the development of rheumatoid arthritis.
\end{abstract}

Keywords: Prolactin, Rheumatoid arthritis, disease activity.

Cite this Article as: Hans-Jacob Haga, Alicia Martin Moreno, Dorte Terp Andersen and Elisabeth Peen (2014), "Serum-Prolactin and the Association to Disease Activity in Patients with Rheumatoid Arthritis," Research in EndocrinologyVol. 2014 (2014), Article ID 396352, DOI: 10.5171/2014.396352 


\section{Introduction}

The hormone prolactin (PRL) is secreted from the pituitary gland and other organs and cells, particularly lymphocytes. The hormone has immunstimulatory effects and may promote autoimmunity, mainly by inhibition of negative selection of autoreactive B lymphocytes as described by Orbach H et. al .(2007) and Chuang E et. al. (2007). PRL is a cytokine, and enhances the the proliferative response to specific antigens and mitogens as demonstrated by Athreya B.H et. al.(1993). Hyperprolactinemia (HPRL) is observed in autoimmune diseases like Systemic Lupus Erythematosus (SLE), Rheumatoid Arthritis (RA), psoriasis, celiac disease, Sjögren's syndrome, Hashimoto's thyrioiditis and Systemic Sclerosis as reviewed by Shelly S et. al. (2012).

It has been suggested by Chikanza I.C (1996) that excessive PRL secretion may be of pathogenic importance in RA. Increased level of s-PRL has been reported in patients suffering from RA demonstrated Zoli A et. al. (2002), Ram S et. al. (2004), Seriolo B et. al. (2002), and Fojtikova M et. al. (2010), and there has been reported a correlation between disease activity and the level of PRL in synovial fluid, as well as a correlation of s-PRL to the total Larsen radiographic score Fojtikova $M$ et.al. (2010). However, the data demonstrating an association between s-PRL level and disease activity are inconsistent as demonstrated by Gutierrez M.A et. al. (1999), Berczi I et. al. (1987), and Nagy E et. al. (1991). None of the present studies, however, have correlated s-PRL to modern disease activity scores such as DAS 28 commonly used in daily clinical practice and in research.

In the present study we analyzed the serum level of prolactin in 307 treated patients with RA, and its correlation to disease activity, laboratory parameters and demographic data. The hypothesis to be tested is: s-PRL correlates to disease activity in patients with RA.

\section{Methods}

At the outpatient clinic at Sydvestjysk sygehus in Esbjerg, about 700 patients with RA were treated and regularly monitored. Among these we included 307 patients in the period from september 2005 to october 2006 after they had given a written informed conscent. The patients were diagnosed with RA according to the ACR1988 criteria as defined by Arnett F.C et. al. (1988), and an additional inclusion criteria was age $>18$ years.

Controls were not included as the main aim of our study was to study correlation between serum prolactin and disease activity of RA, and not a study of the serum level of prolactin in RA patients versus controls.

Four physicians participated in the study, and the patients were evaluated at their regular visits by the disease activity score DAS 28, (3w- CRP) , pain vas score range 0100, and ordinary blood samples. Blood samples were also analyzed for the presence of Rheumatoid Factor by an ELISA technique, and for anti-CCP by the ELISA IgG system on the UniCap 100 from Pharmacia Diagnostics. Blood samples for analysis were collected between 10.00 and $13.00 \mathrm{am}$., and were then stored at $-80^{\circ} \mathrm{C}$.

Prolactin was analyzed by a double sandwich immune analysis using polyclonal goat antibody against PRL (ADVIA Centaur), and all samples were analyzed on the same day. The laboratory defined the normal level of s-prolactin for women to be < $637 \mathrm{miu} / \mathrm{l}$, and for men < $456 \mathrm{miu} / \mathrm{l}$,

\section{Statistical Methods}

Comparing groups of variables were performed using Chi-square test and oneway - ANOVA test. P-values < 0.05 were regarded as statistically significant. 
Correlation analysis was performed by partial correlation analysis and Spearman rank correlations.

\section{Results}

307 patients with RA participated, 210 women (68.4\%) and 97 men (31.6\%). The mean age at examination was 62.8 years (19-87 years), and the mean time since diagnosis was 10.6 years (0-50 years). Positive rheumatoid factor (RF) was detected in 247 patients (80.5\%), and positive anti-CCP was detected in 207 patients $(67.4 \%)$.

The mean pain VAS score was 29. 93 (0100). Rheumatic nodules were observed in $23.4 \%$ of the patients, and vasculitis in 1 patient.

Among the 307 RA-patients examined, 303 patients had a s-PRL level within the normal range as defined $<637$ and $<456$ $\mathrm{mlU} / \mathrm{l}$ for women and men respectively. Four patients had high serum level of PRL defined as females $>637 \mathrm{mIU} / \mathrm{L}$, and males $>456 \mathrm{mIU} / \mathrm{L}$. They were all females, 3 of them being anti-CCP positive, age 32-63 years, none were presently on prednisolone, and only one of them had been treated with biologics. They all had low DAS28 score at the examination, being $1.97,1.42,1.70$ and 1.15 respectively (Figure I). The patient with the highest level of s-PRL $3122 \mathrm{miU} / \mathrm{l}$ was lactating after giving birth.

As shown in Table I, the serum level of PRL was higher in females vs. males, and in younger $(\leq 45$ years) vs. older patients. There was a non-significant trend of higher PRL serum level in short ( $\leq 1$ year) vs.long disease duration, while there was no significant differences in the various groups of patients differing in serology and treatment.

There was a moderate negative nonsignificant correlation of s-PRL to DAS28 score $(r=-0.08, p=0.21)$. Serum-PRL was not significantly different in RF positive/negative, nor in anti-CCP positive/negative patients. There was no correlation of s-PRL to the number of swollen or tender joints, pain or CRP.

\section{Discussion}

It has been suggested by Chikanza I.Cet.al (1996) that excess prolactin levels may be of pathogenic importance in rheumatoid arthritis. This view is based on the demonstrated immunmodulating effect of prolactin demonstrated by Orbach $\mathrm{H}$ et. al. (2007), Chuang E et. al. (2007), Athreya B.H et. al. (1993), and Shelly S et. al. (2012), supported by several studies demonstrating increased serum level of prolactin in patients with rheumatoid arthritis Zoli A et. al .(2002), Ram S et. al. (2004), Seriolo B et.al. (2002), and Fojtikova M et. al. (2010). Additionally it has been reported a correlation between disease activity and the level of PRL in synovial fluid, and a correlation of s-PRL to the total Larsen radiographic score as demonstrated by Fojtikova M et. al. (2010), implicating that prolactin may play a role in disease severity and the process of joint damage.

However, the data demonstrating an association between s-PRL level and disease activity are inconsistent as demonstrated by Gutierrez M.A et. al. (1999), Berczi I et. al. (1987), and Nagy E et. al. (1991). This discrepancy may be due to the use of different tools to analyze disease activity in RA. Some of these tools have been shown not to reflect disease activity of RA, however, and has been replaced by more specific disease activity scores such as DAS 28, now in daily use in clinical practice. We are the first to correlate the disease activity score DAS 28 to the serum level of prolactin in a large population of patients.

We chose DAS 28- 3w for scoring the disease activity as it has been proposed that in established RA it is better to use the DAS index with only 3 variables, as global health or patient global assessment of disease activity can be considered mixed variables that combine the effects of the disease process and damage as suggested by Van Gestel A. M et al (1999). 
In the present study 303 out of 307 RA patients had a s-PRL level within the defined normal range, while 4 patients had high serum level (hyperprolactinemi HPRL), giving a 1, $3 \%$ prevalence of HPRL. The rate of HPRL in a healthy population is reported to be $0.4-3 \%$ as shown by Allen S.H et. al. (1996), Biller B.M et. al. (1999), and Miyai K et. al. (1986).

It has recently been suggested by Adán $\mathrm{N}$ et. al. (2013), based on results from animal studies, that prolactin has a protective effect against inflammation-inducedchondrocyte apoptosis and that hyperprolactinemia has a therapeutic potential to reduce permanent joint damage and inflammation in RA. This observation is interesting in view of our observation that our patients with high levels of prolactin HPRL all had low disease activity. It also indicates that the effect of prolactin is locally in the joints and therefore may not be reflected at the serum level.

As a conclusion, we demonstrated that sPRL did not correlate to disease activity, serology or demographic factors in 307 treated patients with rheumatoid arthritis.

We therefore question the hypothesis that PRL may play a role in disease severity and the development of rheumatoid arthritis in humans.

Table I. Differences in Serum Level of Prolactin in 307 Patients with Rheumatoid Arthritis, Comparing Various Demographic, Clinical and Serological Variables

\begin{tabular}{|l|l|l|}
\hline & $\begin{array}{l}\text { Se-Prolactin } \\
\text { mIU/L }\end{array}$ & p-value \\
\hline $\begin{array}{l}\text { Female/male } \\
210 / 97\end{array}$ & $177.8 / 122.6$ & 0.026 \\
\hline $\begin{array}{l}\text { Age at examination } \\
\leq 45 \text { years/> 45 years } \\
30 / 277\end{array}$ & $294.2 / 145.9$ & $<0.001$ \\
\hline $\begin{array}{l}\text { CRP } \\
\text { high/ normal } \\
214 / 92\end{array}$ & $166.3 / 146.6$ & NS \\
\hline $\begin{array}{l}\text { Rheumatoid factor } \\
\text { pos/ negative } \\
247 / 60\end{array}$ & $158.7 / 167.4$ & NS \\
\hline $\begin{array}{l}\text { Anti-CCP } \\
\text { positive/negative } \\
207 / 100\end{array}$ & $158.3 / 165.3$ & NS \\
\hline $\begin{array}{l}\text { Disease duration } \\
\text { Short }(\leq 1 \text { year)/ Long }(>1 \text { year) } \\
65 / 240\end{array}$ & $201.9 / 149.2$ & 0.06 \\
\hline $\begin{array}{l}\text { Prednisolone } \\
\text { Presently on/ presently } \\
\text { not on prednisolone } \\
90 / 217\end{array}$ & $142.2 / 167.9$ & NS \\
\hline $\begin{array}{l}\text { DMARDS } \\
\text { Ever treated } \geq 3 \text { DMARDs/ } \\
\text { treated with less than 3 DMARDs } \\
50 / 257\end{array}$ & $144.0 / 163.6$ & NS \\
\hline $\begin{array}{l}\text { Treated with biologics } \\
\text { Ever treated / } \\
\text { never treated 65/242 }\end{array}$ & $158.3 / 165.3$ & NS \\
\hline $\begin{array}{l}\text { Rheumatic nodules/ } \\
\text { no nodules } \\
71 / 236\end{array}$ & $150.0 / 163.2$ & NS \\
\hline
\end{tabular}


The laboratory defined the normal level of s-prolactin for women to be $<637 \mathrm{miu} / \mathrm{l}$, and for men $<456 \mathrm{miu} / \mathrm{l}$,

Serum Prolactin mIU/L versus DAS 28 score

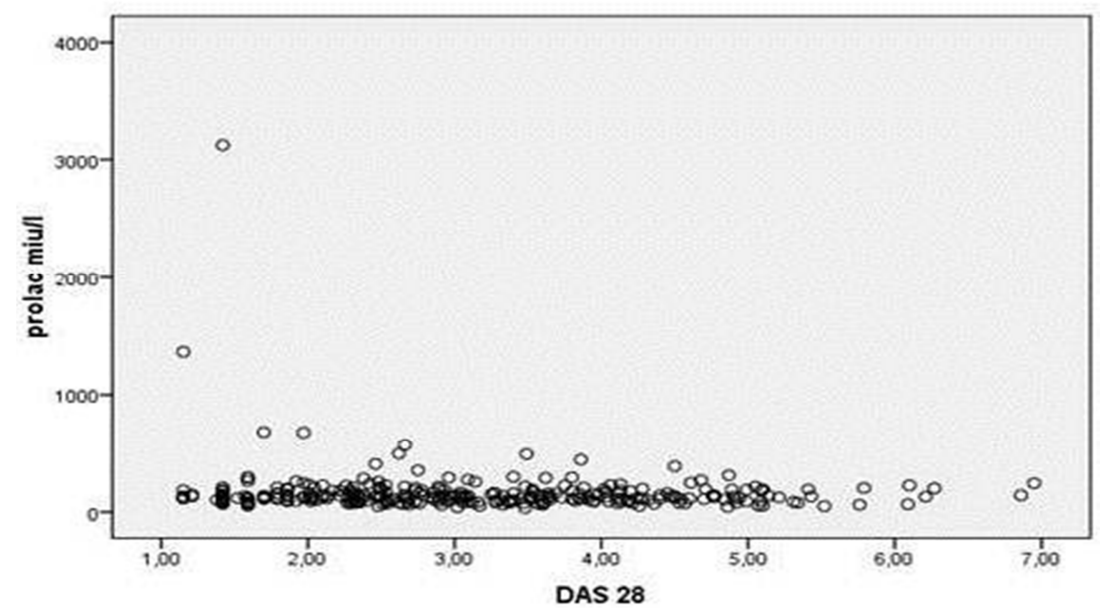

Figure I: Scatterplot for the Serum Level of Prolactin versus DAS 28 Score in 307 Treated Patients with Rheumatoid Arthritis (RA)

The laboratory defined the normal level of s-prolactin for women to be $<637 \mathrm{miu} / \mathrm{l}$, and for men $<456 \mathrm{miu} / \mathrm{l}$,

\section{Acknowledgments}

We are grateful for excellent help given by the clinical and laboratory staff at the Department of Rheumatology at The Sydvestjysk sygehus, especially Dr. Yusuf Naderi, Karin Bundesen, Jytte Krause, and Pia Rasmussen.

We appreciate Kvinherrad Rheumatism Association and Stord Rheumatism Association for their funding of the project. We also thank the patients for their participation.

\section{References}

Adán, N., Guzman-Morales, J., LedesmaColunga, M. G., Perales-Canales, S. I., Quintanar-Stephano, A., López-Barrera, F., Méndez, I., Moreno-Carranza, B., Triebel , J., Binart, N., Martinez de la Escalera, G., Thebault, S. \& Clapp, C. (2013). "Prolactin Promotes Cartilage Survival and Attenuates Inflammation in Inflammatory Arthritis," Journal of Clinical Investigation 123(9):3902-13
Allen, S. H., Sharp, G. C., Wang, G., Conley, C., Takeda, Y., Conroy, S. E. et al. (1996). "Prolactin Levels and Antinuclear Antibody Profiles in Women Tested for Connective Tissue Disease," Lupus 5:30-7

Arnett, F. C., Edworthy, S. M., Bloch, D. A., Mcshane, D. J. et al. (1988). "The American Rheumatism Association 1987 Revised Criteria for the Classification of Rheumatoid Arthritis," Arthritis \& Rheumatism 31: 315-324.

Athreya, B. H., Pletcher, J., Zulian, F., Weiner, D. B. \& Williams, W. V. (1993). "Subset-Specific Effects of Sex Hormones and Pituitary Gonadotropins on Human Lymphosyte Proliferation in Vitro," Clinical Immunology and Immunopathology 66:201211.

Berczi, I., Cosby, H., Hunter, T., Barager, F. D., Mcneilly, A. S. \& Friesen, H. G. (1987). "Decreased Bioactivity of Circulating Prolactin in Patients with Rheumatoid Arthritis," British Journal of Rheumatology 26:433-6

Biller, B. M., Luciano, A., Crosignani, P. G., Molitch, M., Olive, D., Rebar, R. et al. (1999). "Guidelines for the Diagnosis and 
Treatment of Hyperprolactinemia," The Journal of Reproductive Medicine 44:107584

Chikanza, I. C. \& Grossman, A. B. (1996). "The Neuroendocrine Immunology of Rheumatoid Arthritis," Baillière's Clinical Rheumatology 10:273-93.

Chuang, E. \& Molitch, M. E. (2007). "Prolactin and Autoimmune Diseases in Humans," Acta Biomedica 78; Suppl 1:255261.

Fojtiková, M., Tomasová Studýnkova, J., Filková, M., Lacinová, Gatterová, J., Pavelka, K., Vencovský, J. \& Senolt, L. (2010). "Elevated Prolactin levels in Patients with Rheumatoid Arthritis: Association with Disease Activity and Structural Damage," Clinical and Experimental Rheumatology 28(6):894-54.

Gutierrez, M. A., Garcia, M. E., Rodriguez, J. A., Mardonez, G., Jacobelli, S. \& Rivero, S. (1999). "Hypothalamic-Pituitary-Adrenal Axis Function in Patients with Active Rheumatoid Arthritis: A Controlled Study Using Insulin Hypoglycemia Stress Test and Prolactin Stimulation," The Journal of Rheumatology 26:277-81

Miyai, K., Ichihara, K., Kondo, K. \& Mori, S. (1986). "Asymptomatic Hyperprolactinaemia and Prolactinoma in the General Population - Mass Creening by Paired Assays of Serum Prolactin," Clinical Endocrinology 25: 549-54.
Nagy, E., Chalmers, I. M., Baragar, F. D., Frisen, H. G. \& Berczi, I. (1991). "Prolactin Deficiency in Rheumatoid Arthritis," The Journal of Rheumatology 18:1662-8

Orbach, H. \& Shoenfeld, Y. (2007). "Hyperprolactinemia and Autoimmune Diseases," Autoimmunity Reviews 6:537542.

Ram, S., Blumberg, D., Newton, P., Anderson, N. R. \& Gama, R. (2004). "Raised Serum Prolactin in Rheumatoid Arthritis: Genuine or Laboratory Artefact?," Rheumatology 43: 1272-4.

Seriolo, B., Ferreti, V., Sulli, A., Caratto, E., Fasciolo, D. \& Cutolo, M. (2002). "Serum Prolactin Concentrations in Male Patients with Rheumatoid Arthritis," Annals of the New York Academy of Sciences 966: 258-62.

Shelly, S., Boaz, M. \& Orbach, H. (2012). "Prolactin and Autoimmunity," Autoimmunity Reviews: A465-A470.

Van Gestel, A. M. \& Stucki, G. (1999). "Evaluation of Established Rheumatoid Arthritis," Baillieres Best Practice \& Research Clinical Rheumatology 13:629-44

Zoli, A., Lizzio, M. M., Ferlisi, E. M., Massafra, V., Mirone, L., Barini, A. et al.(2002). "ACTH, Cortisol and Prolactin in Active Rheumatoid Arthritis," Clinical Rheumatology 21:289-93. 